\title{
Analyses of fold profiles by changing weight parameters of NURB curves
}

\author{
Manash Pratim Gogoi ${ }^{1}$, Soumyajit Mukherjee ${ }^{2, *}$ and Tapos K Goswami ${ }^{3}$ \\ ${ }^{1}$ Department of Geology, Sibsagar College, Joysagar, Sivasagar 785 665, India. \\ ${ }^{2}$ Department of Earth Sciences, Indian Institute of Technology Bombay, Powai, Mumbai 400 076, India. \\ ${ }^{3}$ Department of Applied Geology, Dibrugarh University, Dibrugarh 786 004, India. \\ *Corresponding author.e-mail: soumyajitm@gmail.com
}

MS received 29 January 2017; accepted 20 April 2017; published online 6 October 2017

Analyses of Non-Uniform Rational B-spline (NURB) curve by varying weights at its nodal points and projection ratio produce several kinetically plausible symmetric and asymmetric fold morphologies in $2 \mathrm{D}$ promptly and efficiently with varied overall geometries, curvature of limbs, sharpness/bluntness of hinges, extent of hinge zone, tightness/interlimb angles, etc. Some of these folds are new geometries what other approaches, such as those with Bézier curve, did not produce so far. Natural fold profiles can be matched with NURB curves from photographs.

Keywords. NURB curve; Bézier curve; fold morphologies; interlimb angle; axial plane; curvature.

\section{Introduction}

...the geometry of geological structures must be accurately described before conclusions about their formation can be drawn.

$$
\text { -Bastida et al. (2005) }
$$

Folds are the most widely recognized structures in deformed rocks (Hudleston and Treagus 2010). Their geometries are commonly represented by their 2D profile sections, which are governed primarily by the rheology of the rocks that flex (e.g., Fletcher 1979). Ghassemi et al. (2010) linked bulk shortening with the fold geometries. Therefore, specifying the fold geometries can connote the rheology and/or bulk shortening of the rock (Hudleston and Lan 1994). Various geometric classifications of folds are available (Ghosh 1993). To name a few, folds have been classified as gentle, open, closed, tight and isoclinal depending on their interlimb angles (Fleuty 1964). Likewise, depending on the dip amounts of the axial planes, folds have been classified as upright/vertical, subvertical, steeply or moderately or gently inclined and recumbent (e.g., Wills and Willis 1929). The ratio between fold amplitude $(A)$ and base length $(L)$ is called the aspect ratio $R=A L^{-1}$ (Aller et al. 2004). Ramsay (1967) used dip isogons to classify folds into three broad 'classes'. By quantifying harmonic waveforms, many authors (e.g., Srivastava and Gairola 1997; Tripathy and Gairola 1999) performed Fourier analysis of fold shapes. Chapple $(1968,1969)$ analyzed finite amplification, wavelengths and interlimb angles of folds within viscous materials inside a non-Newtonian layer. Stabler (1968) studied fold shapes with the help of harmonic coefficients of the Fourier series (see Lisle et al. 2006 for more analyses on fold profiles). Hudleston (1973) furthered this method and suggested $5 \times 6$ geometries of fold. This means that 
a total of 30 types of fold geometries are presented in a matrix with 5 rows and 6 columns. Works by Stabler (1968) and Hudleston (1973) were expedited using curve fitting regression method through computer analyses by Stowe (1988). Also note that Twiss (1988) presented a method devoid of Fourier analysis to simulate both symmetric and asymmetric fold profiles. Several researchers have also used power functions (Bastida et al. 1999) and parametric functions in addition to other constraints like amplitude, wavelength data, horizontal and vertical projections of the handling points (Srivastava and Lisle 2004; Ghatak et al. 2005; Srivastava et al. 2010) to describe and analyze shapes of folds and other geological objects (Evans et al. 1985) with computer-aided programmes. Handling points are basically control points to generate the curves/fold morphologies and are not inflection points. A control point, on the other hand, determines the shape of a spline curve in a coordinate reference frame. Its coordinate depends on the type of reference frame whether it is $2 \mathrm{D}$ or $3 \mathrm{D}$ vector-graphics (Salomon 2007). The reference frame is the $\mathrm{X}-\mathrm{Y}$ coordinate system.

Liu et al. (2009a, b) used quadratic Bézier curves and simulated several fold shapes with the help of axial lift-up ratio of the central part and interlimb angles. Bastida et al. (2005) reviewed in detail how curves are fitted with fold profiles. They referred that conic sections in general are most feasible to fit with the fold profiles.

In this work, we simulate different fold morphologies using NURB curves. A new range of folds were produced in this method. NURB curves have previously been used in geo-resource studies (Zhong et al. 2006) and in extrapolating geoscientific information (Sprague and de Kemp 2005), but not in fold morphologies to our knowledge.

\section{B-spline and NURB curves}

Bézier curve (or Bernstein-Bézier curve or Bspline) is a $2 \mathrm{D}$ shape based on parametric equation as used by Marco and Martínez (2007) and many other graphic designers, viz., Sederberg for Autodesk Inc. (e.g., Sederberg, internet reference; Sederberg et al. 2003, 2008; Wojtal 2001)

$$
C(t)=\sum_{i=0}^{n} P_{i} B_{i, n}(t), \quad t \in[0,1]
$$

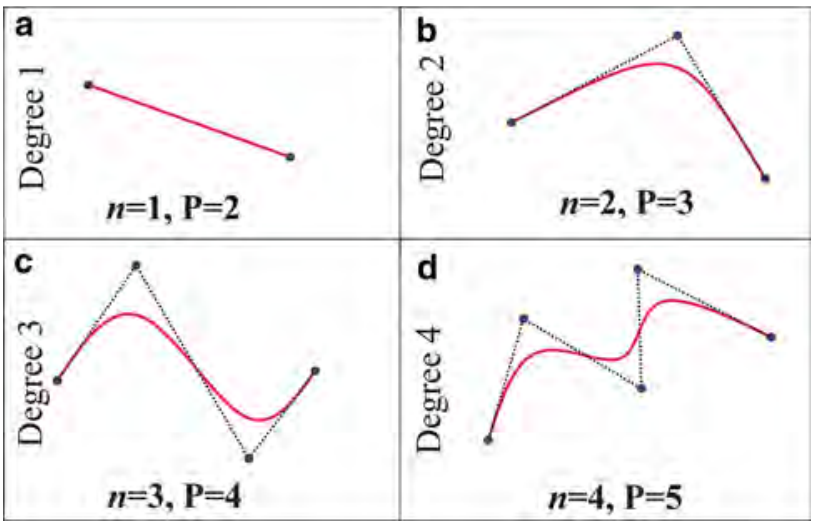

Figure 1. Bézier curves of different degrees and control points $(P)$ : (a) Degree $1(n=1, P=2)$, (b) quadratic or degree $2(n=2, P=3),(\mathbf{c})$ cubic or degree $3(n=3$, $P=4)$, and $(\mathbf{d})$ higher or degree $4(n=4, P=5)$.

where $B_{i, n}$ is the blending functions; $B_{i, n}(t)$ is a Bernstein polynomial as in equation (2). $P_{i}$ is the location of controlling/handling points. $n$ is the degree of curve. A set of $(n+1)$ numbers of control points $P_{0}, P_{1}, \ldots, P_{n}$ exist. As per Lorentz (1953):

$$
B_{i, n}(t)=\left(\begin{array}{c}
n \\
i
\end{array}\right)(1-t)^{n-i} t^{i}, \quad i=0,1, \ldots, n
$$

Here, $\left(\begin{array}{l}n \\ i\end{array}\right)$ is the binomial coefficient, i.e., $\frac{n !}{i !(n-i) !}$. If $n=2, B_{0,2}=(1-t)^{2}, B_{1,2}=2 t(1-t)$ (here the symbol '!' means factorial) and $B_{2,2}=t^{2}$. Substituting values of $B_{0,2}, B_{1,2}$ and $B_{2,2}$, equation (1) gives a quadratic Bézier equation of second degree (figure 1b):

$$
C(t)=(1-t)^{2} P_{0}+2(1-t)(t) P_{1}+t^{2} P_{2}
$$

$P_{0}, P_{1}$ and $P_{2}$ are the three controlling points in equation (3). The curve is tangent to $P_{1}-P_{0}$ and $P_{n}-P_{n-1-}$ at the end points. Equation (1) can similarly produce cubic and still higher order Bézier curves (figure 1c, d).

A rational (or ratio of polynomial) Bézier curve is also referred as the NURB curve (non-uniform rational B-spline curve) (Piegl and Tiller 1997a):

$$
R(t)=\frac{\sum_{i=0}^{n} B_{i, n}(t) w_{i} \mathbf{P}_{i}}{\sum_{i=0}^{n} B_{i, n}(t) w_{i}} .
$$

Here $w_{i}$ is the weight of $P_{i}\left(x_{i}, y_{i}, w_{i}\right)$, which is the last ordinate of the homogeneous point $P_{i, w}$. An example of 2 nd degree $(n=2)$ rational quadratic 


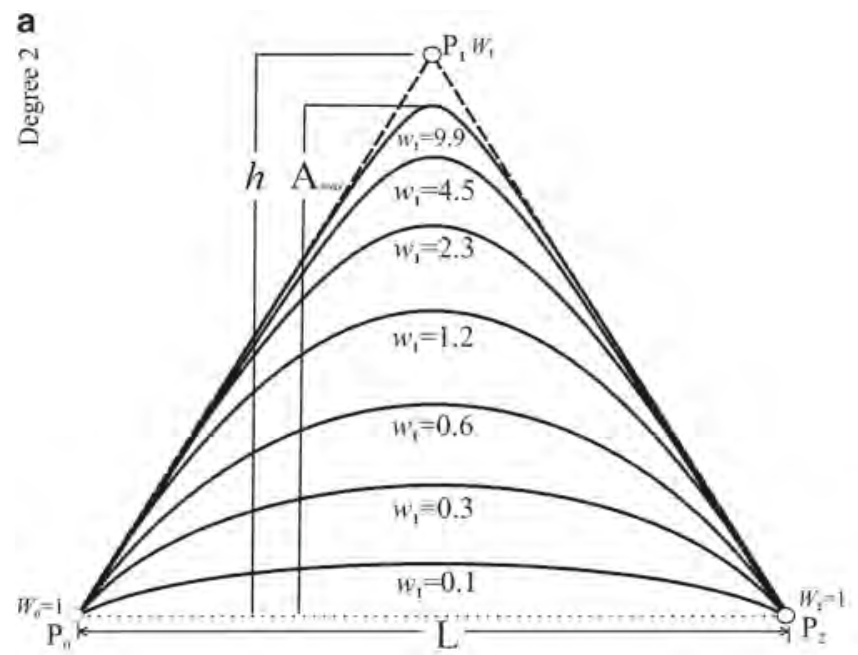

b
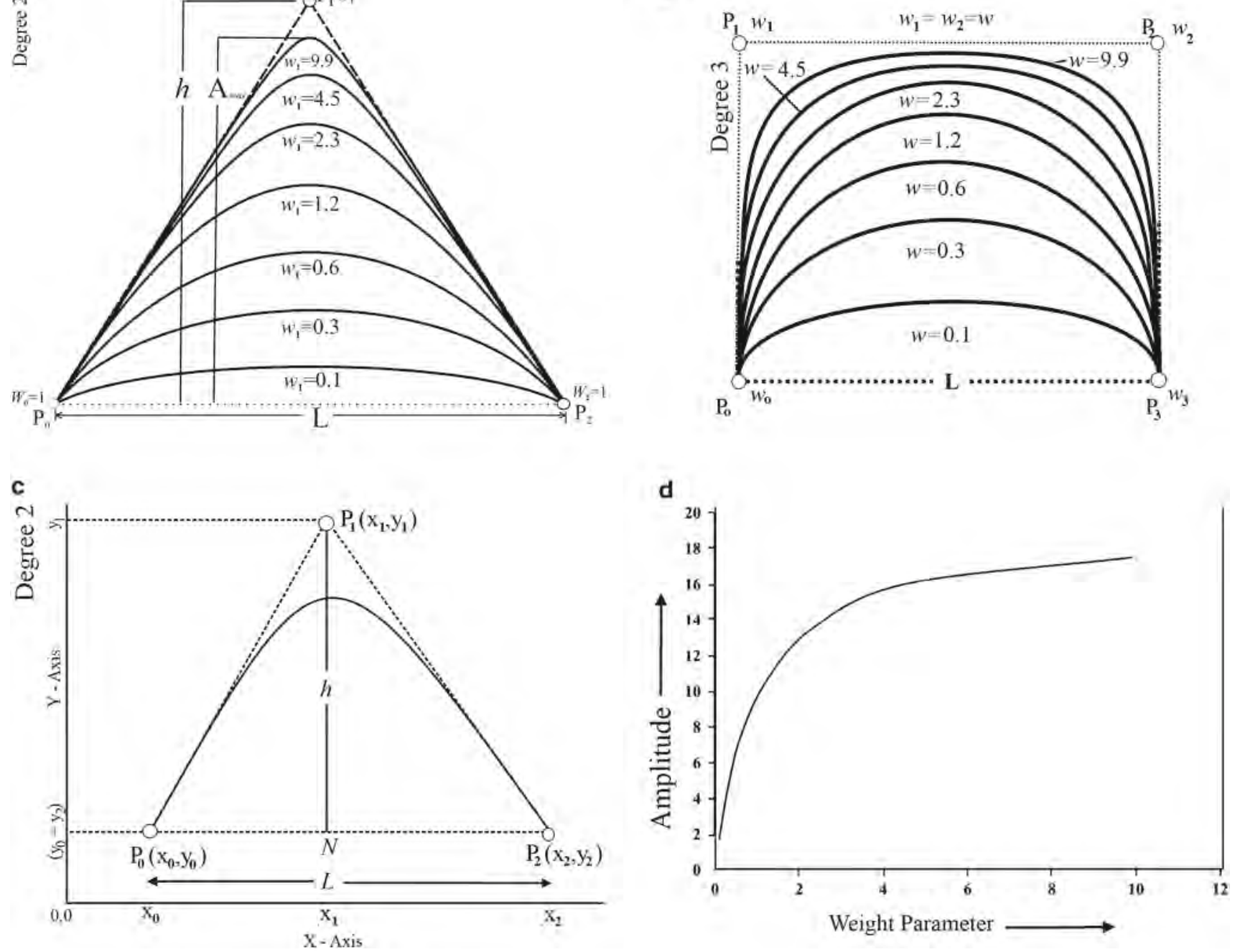

Figure 2. Different conic sections developed from equation (4) keeping $w_{\mathbf{0}}=w_{\mathbf{1}}=1$ constant and by changing the value of $w_{1}$ from $0.1\left(w_{1}^{\text {min }}\right)$ up to $9.9\left(w_{1}^{\max }\right)$ resulting: (a) 2nd degree NURB curves (quadratic) resemble symmetric folds of increasing tightness/falling interlimb angle. (b) 3rd degree NURB curves (cubic) resemble double hinge character of box folds. (c) A quadratic Bézier curve with $h=y_{1}-y_{0}$ and $L=x_{2}-x_{0}$. (d) Logarithmic relation between fold amplitude (A) and weight parameter $\left(w_{1}\right)$.

Bézier curve equation can be derived from equation (4) as (figure 2a):

$$
R(t)=\frac{(1-t)^{2} w_{0} P_{0}+2 t(1-t) w_{1} P_{1}+t^{2} w_{2} P_{2}}{(1-t)^{2} w_{0}+2 t(1-t) w_{1}+t^{2} w_{2}}
$$

Here $w_{0}, w_{1}, w_{2}$ are the weights of $P_{0}, P_{1}$ and $P_{2}$, respectively. $w_{1}>1$ represents a hyperbola; $w_{1}=1$, a parabola; and $w_{1}<1$, an ellipse. The first case would not indicate profile of a single fold. The parabolic profile would indicate (simulated by other workers such as Ghassemi et al. 2010) doming of a viscous material that behave as a Newtonian fluid, with (Mukherjee et al. 2010) or without overburden (Mukherjee and Mulchrone 2012). A sheath fold produced by intense ductile simple shear (e.g., Mukherjee 2015) in cross-section is elliptical (i.e., $\left.w_{1}<1\right)$.

We have three controlling points in a second degree curve, viz., $P_{0}\left(x_{0}, y_{0}\right), P_{1}\left(x_{1}, y_{1}\right)$ and $P_{2}\left(x_{2}\right.$, $\left.y_{2}\right)$ as shown in figure $2(\mathrm{c})$. Distance between $P_{0}$ and $P_{2}$ can be considered as base-length $L=$ $x_{2}-x_{0}$. On other hand, projection length $h$ is the perpendicular separation between base length $L$ to point $P_{1}$, taking $y_{0}=y_{2}, h=y_{1}-y_{0}=$ $y_{1}-y_{2}$. Projection ratio $R=h L^{-1}$ can be taken as a parameter to change fold shapes. For cubic or higher degree Bézier curves, we can take $h=$ $y_{1}-y_{0}=y_{2}-y_{3} ;$ and $L=x_{3}-x_{0} ;$ as in figure 2(b). Figure 2(b) simulates, from $w=0.1$ up to about 2.3 , round hinge folds consisting of broad 
hinge zones. At much higher $w$ values (e.g., 9.9), two hinge points develop and in between nearly a straight line. This resembles nearly a box fold geometry. Almost similar geometries of folds can be produced by doming/flow of non-Newtonian ductile rock materials (Turcotte and Schubert 2002).

Relationship between the weight parameter $w_{1}$ and amplitude $(A)$ is a logarithmic increment with increasing the value to $w_{1}$; i.e., $A$ increases as $f\left(w_{1}\right)=\ln \left(w_{1}\right)$, as in figure $2(\mathrm{~d})$. Maximum value of amplitude remains $<h$.

Changing the distance between $P_{0}$ and $P_{2}$ and changing the values of $w_{1}$ in equation (5), different shapes of folds can be created as in figure 3(a). By putting $n=3$ (equation 4 ), third degree cubic curves can be prepared with four control points $P_{0}, P_{1}, P_{2}$ and $P_{3}$ and weight parameters $w_{0}, w_{1}$, $w_{2}$ and $w_{3}$, respectively. By repeating the procedure while keeping $w_{0}=w_{3}=1$ as constant and changing the values of $w_{1}=w_{2}$ from 0.1 up to 9.9, we get more fold patterns as in figure 3(b).

Analyzing the characteristics of these fold forms generated by 2 nd and 3rd degree NURBs (figure 3a, b), a range of fold geometries - straight limbs, sharp/rounded hinges, kinks, box like, circular arc, different tightness/interlimb angles, etc., can be produced. Figure 4(a, b) shows the scheme of fold shapes.

Progressive increasing degrees of asymmetry in fold morphologies can also be created using NURB curves by adapting similar procedure as shown in figure 2 (a) by changing the position of $P_{1}$ (figure 5) and keeping $w_{0}=w_{2}=1$, constant. The degree of asymmetry increases and the dip amounts of axial plane falls as one keeps increasing the $w_{1}$ magnitudes.

\section{Exercises with two natural folds}

We take two natural fold photographs to utilize NURB curve exercise (figures 6-8). We choose a tight isoclinal fold, with uneven thickness of limbs and hinge regions (Akjoujt, Inchiri region, W Mauritania; figure 1.34 in Mukherjee 2015; here figures $6-7$ ). NURB curve tool has been used to draw the 2nd degree curve, and weight parameter of point $P_{1}$ has been changed in the transform panel. Changes in other parameters have been observed by varying the weight parameter $w_{1}$ (by 1,4 and 5.3) for the point $P_{1}$. For this NURB, $L=6.42$ (distance between $P_{0}$ and
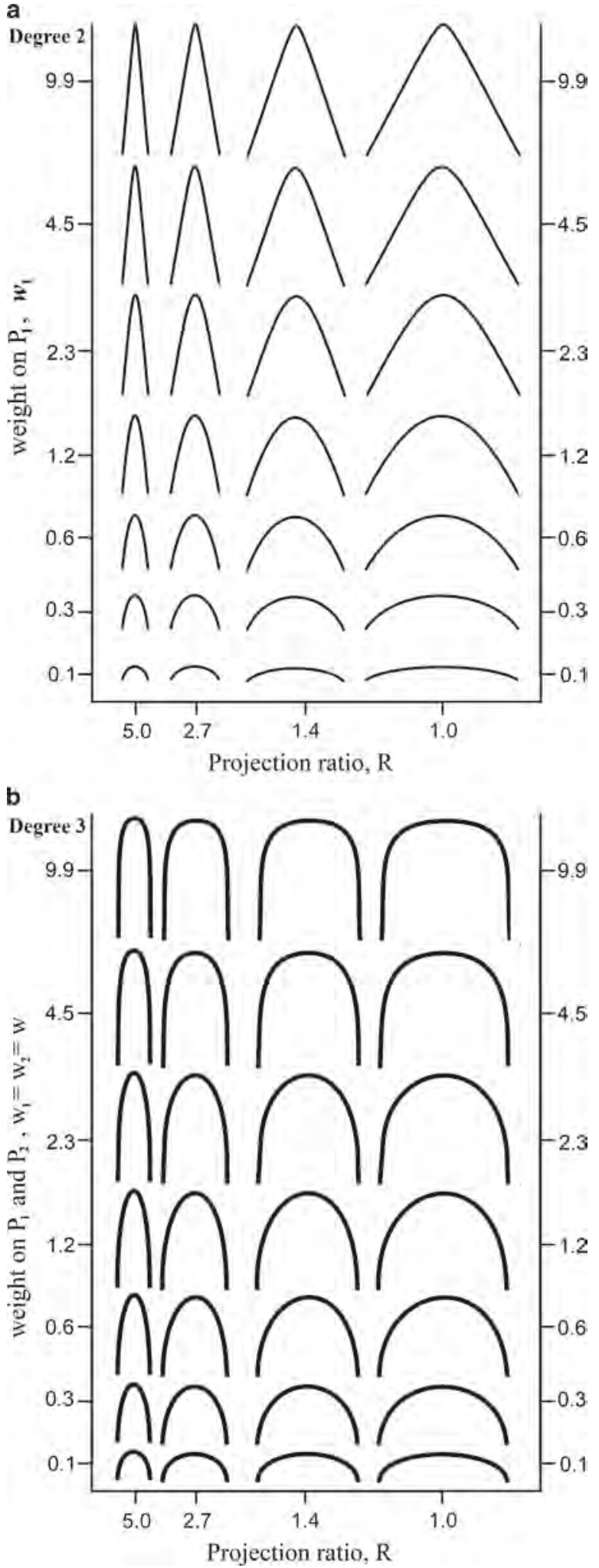

Figure 3. (a) Different types of 2nd degree $(n=2)$ quadratic NURB folds generated by increasing value of $w_{1}$ from 0.1 to 9.9 with increasing $R=h L^{-1} .7 \times 4$ possibilities of fold geometries shown. (b) 3rd degree $(n=3)$ cubic NURB folds generated by increasing value of $w_{1}=w_{2}=w$ from 0.1 to 9.9 and increasing $R=h L^{-1}$. In all cases, $h$ remains constant. $7 \times 4$ possibilities of fold geometries are shown in the figure. 


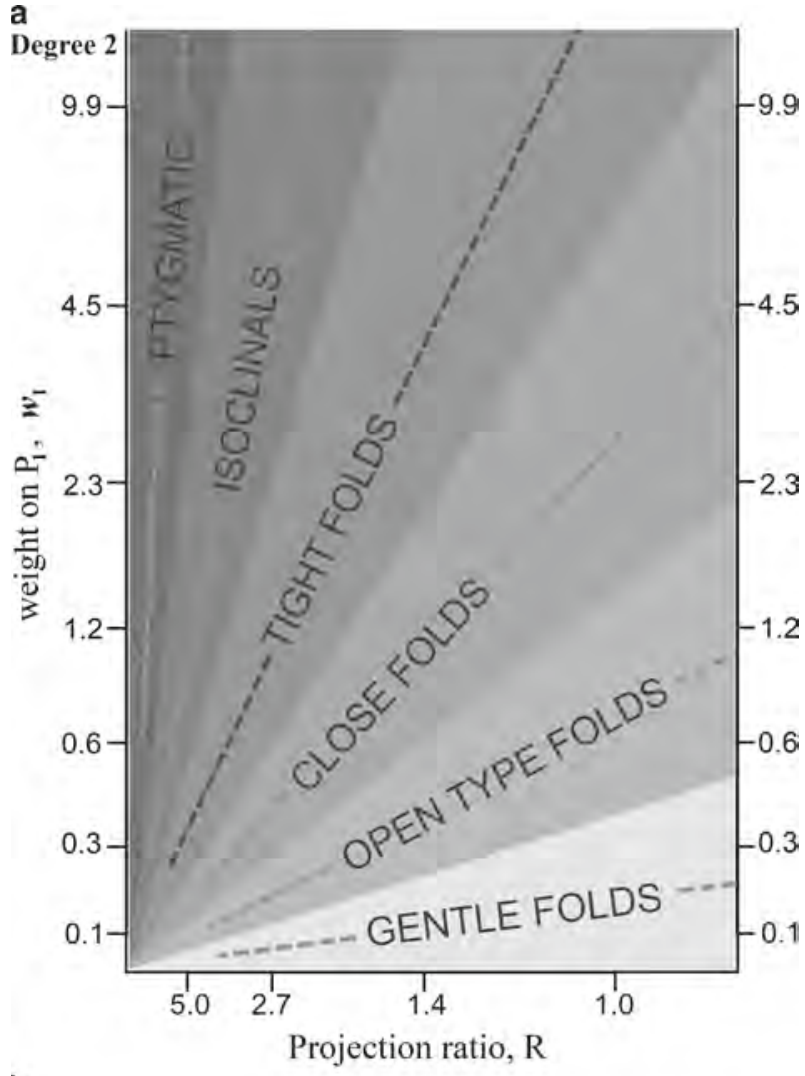

b

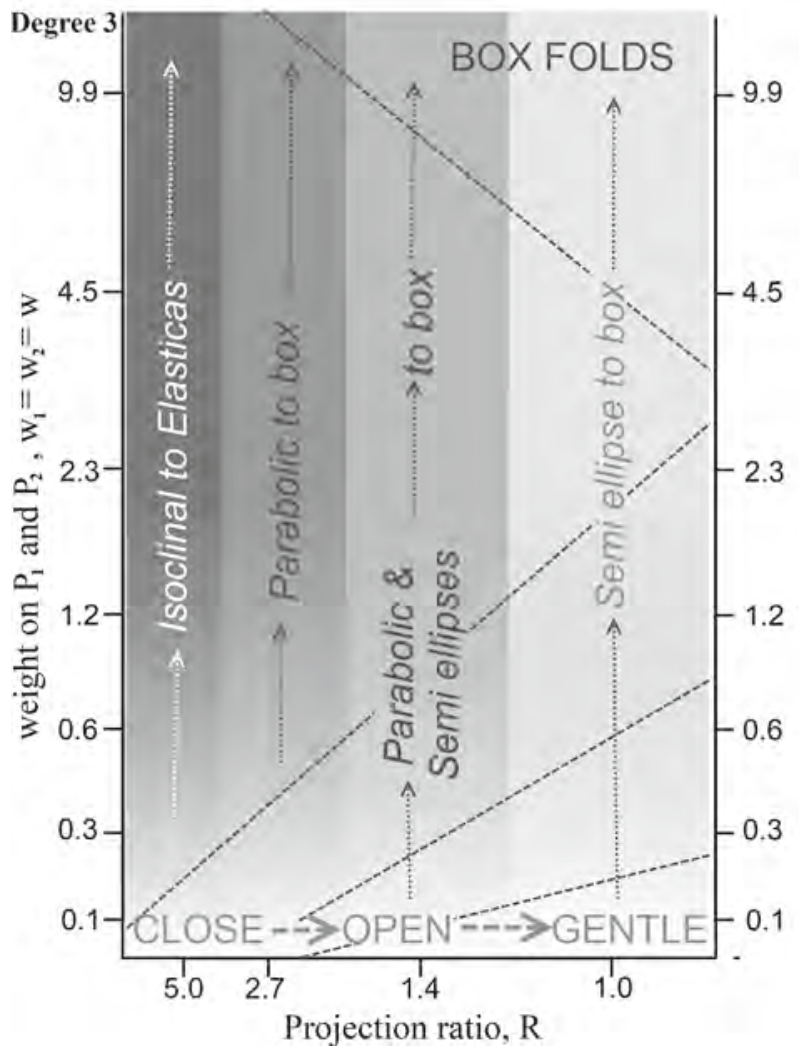

Figure 4. (a) Scheme of fold types generated from 2nd degree NURBs as per figure 3(a, b). (b) Scheme of fold types generated from 3rd degree NURBs as per figure 3(b). In both figures deeper shades indicate tighter folds.

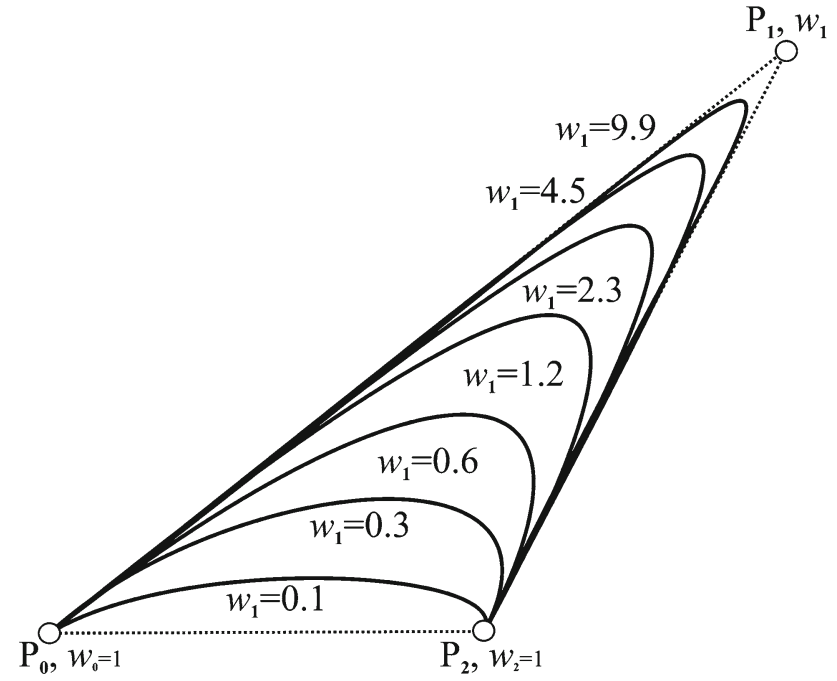

Figure 5. Asymmetric folds generated from equation (5) by changing the position of $P_{\mathbf{1}}\left[x_{1} \neq\left(x_{2-} x_{0}\right) / 2\right]$ and by increasing $w_{1}$ magnitudes.

$P_{2}$ ) and $h=10.62$ (elevation of $P_{1}$ ), projection ratio $R=h L^{-1}=1.65$. The second example is a ptygmatic fold with isoclinal, round hinge and box geometries in banded calc-silicate gneiss hosted within a recrystallized marble matrix (figure 1.57 in Mukherjee 2015; here figure 8). A 3rd degree NURB is drawn over the box fold. The parameters are $h=4.5, L=5.22$ and $R=0.86$. The readers are encouraged to apply NURB curve fitting on natural examples of folds in different scales (e.g., as given in Misra and Mukherjee 2017; Mukherjee and Koyi 2009; Mukherjee 2010a, b, 2011, 2013, 2014a, b).

\section{Discussion and conclusions}

NURB curves (Piegl and Tiller 1997b) have been used in this work to demonstrate a new and quick method of simulating fold profiles. NURB represents conic sections and can produce a different range of morphologies of folds than the Bézier curve. Some of these folds resemble geometries that are expected theoretically from known (such as Newtonian) rheologies of ductile rocks. Previously, Srivastava and Lisle (2004) simulated a range of fold shapes in aspect ratio vs. shape parameter plot by Bézier curve analyses. Those folds had varying interlimb angles/tightness, bluntness/sharpness of the hinge region and curvature of the limbs. Liu et al. (2009a) in their figures 3(b) and 4 presented how fold shape is sensitive to the axial lift-off ratio. Srivastava et al. (2010) generated 


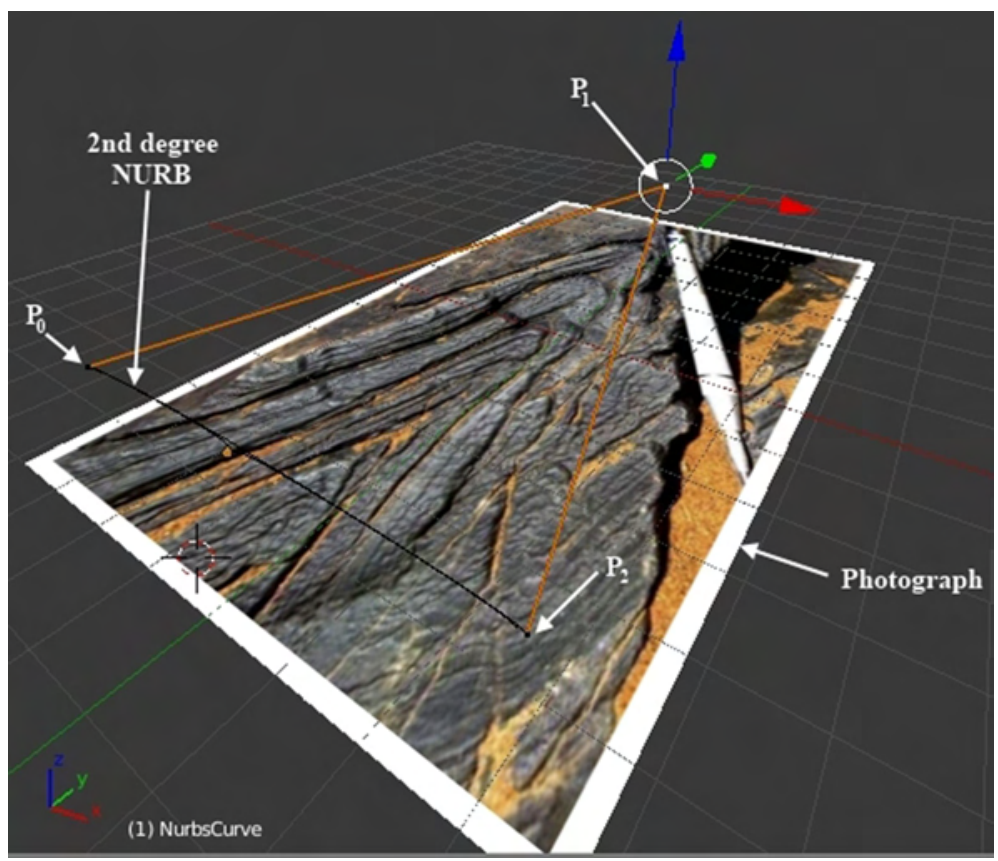

Figure 6. NURB curve tool applied on a natural fold. See section 3 for details.
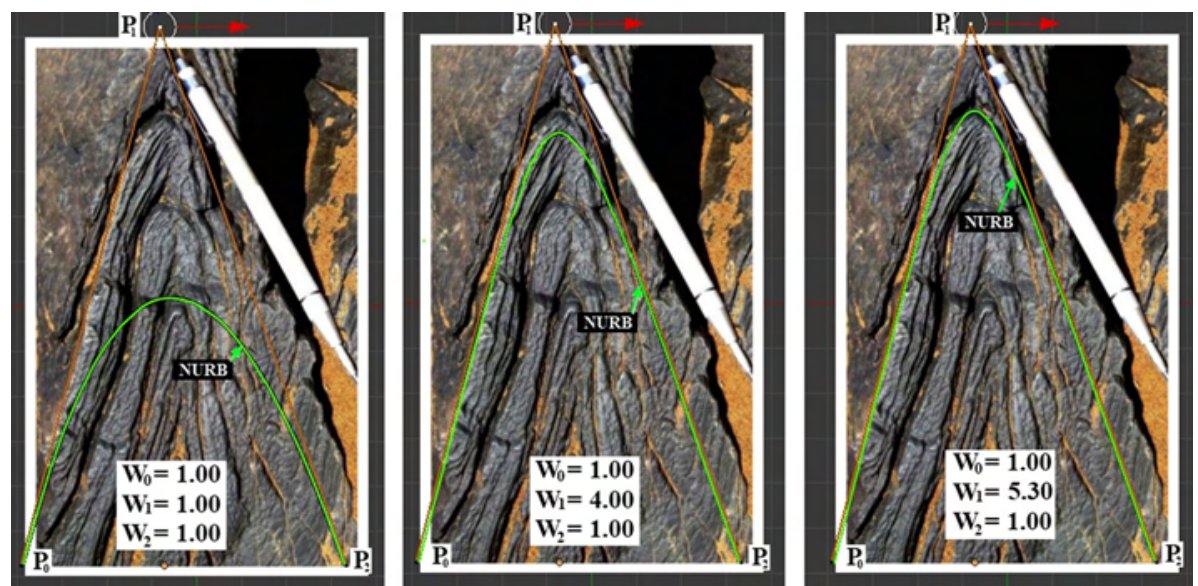

Figure 7. NURB curve tool applied on a natural fold. See section 3 for details.

asymmetric fold geometries by varying the ratio of length of the first Bézier handle and width of the fold while maintaining the aspect ratio constant (their figure 8a). The present work, in line of Srivastava and Lisle (2004), Liu et al. (2009a, b) and Srivastava et al. (2010), simulates geometries of only the extrados or the intrados of the fold. Both symmetric and asymmetric folds were simulated, which are comparable with those done by other methods (figures 2, 3 and 10 of Bastida et al. 2005 ). Figure 3 (a) for high magnitudes of 'weight on $P_{1}^{\prime}\left(w_{1}\right)$ and projection ratio $(R)$ simulate nearly a chevron fold geometry. Such a geometry was not simulated earlier from linear viscous rheology, as per Cruikshank and Johnson (1993).
Doming of fluid/ductile deforming rocks with a Newtonian viscous rheology produces parabolic fold morphology (Johnson and Fletcher 1994). On the other hand, the parabolic fold profiles simulated in figure 3(a) for moderate magnitudes of $w_{1}$ and $R$ could be produced when a ductile rock of Newtonian viscous rheology extrudes with or without overburden. Summarily, we simulated fold profiles that are able to generate for both linear and non-linear rheology of the ductile rock. Two natural fold profiles were modelled using NURB curve.

Bezier curve tool does not provide flexibility to modify curve shape without altering the positions of the handling points. Whereas in case of 


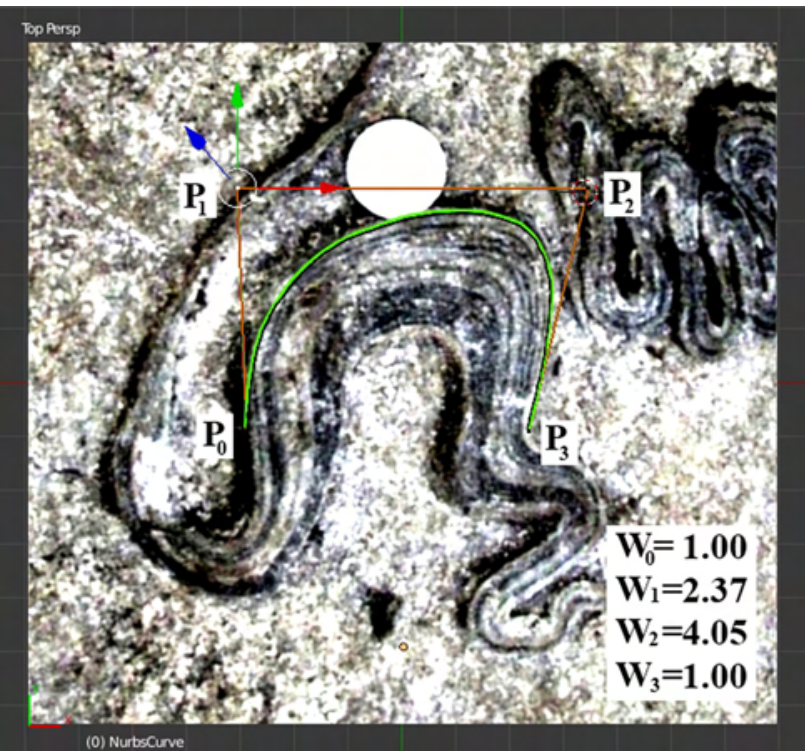

Figure 8. NURB curve tool applied on a natural fold. See section 3 for details. 25-mm diameter coin for scale (photograph by Subhadip Mandal from $\mathrm{N}$ to Munsiari, India).

NURB tool, a curve can be reshaped or transformed into a different shape without changing the positions of handling points and can be achieved by changing the values of weight parameters only.

However, natural non-periodic folds can have even different geometries of its outer- (extrados) and inner- (intrados) layers, which could be typically found within migmatites (Mukherjee and Koyi 2010). In that case, a single fold cannot be uniquely represented by a single NURB- nor a Bézier curve. Using super and sub-ellipses to fit fold profiles can be attempted as future exercises.

\section{Acknowledgements}

SM was supported by CPDA grant of IIT Bombay. Associate Editorial assistance and review by Prof. Saibal Gupta (IIT Kharagpur) and detailed comments by an anonymous reviewer and Eugenio Fazio are acknowledged.

\section{References}

Aller J, Bastida F, Toimil N C and Bobillo-Ares N C 2004 The use of conic sections for the geometrical analysis of folded profile surfaces; Tectonophys. 379 239-254.

Bastida F, Aller J and Bobillo R S 1999 Geometrical analysis of folded surfaces using simple functions; Tectonophys. 21 $729-742$
Bastida F, Aller J, Bobillo-Ares N C and Toimil N C 2005 Fold geometry: A basis for their kinematical analysis; Earth-Sci. Rev. 70 129-164.

Chapple W M 1968 A mathematical theory of finiteamplitude rock-folding; Geol. Soc. Am. Bull. 79 47-68.

Chapple W M 1969 Fold shape and rheology: The folding of an isolated viscous-plastic layer; Tectonophys. 7 97116.

Cruikshank K M and Johnson A M 1993 High-amplitude folding of linear-viscous multilayers; J. Struct. Geol. 15 79-94.

Evans D G, Schweitzer P N and Hanna M S 1985 Parametric cubic splines and geologic shape descriptions; Math. Geol. 17 611-624.

Fletcher R 1979 The shape of single-layer folds at small but finite amplitude; Tectonophys. 60 77-87.

Fleuty M J 1964 Description of folds; Proc. Geol. Assoc. 75 461-492.

Ghatak A, Sahay A and Srivastava D C 2005 Application of Bézier curves for analysis of symmetric fold shapes; Him. Geol. 26 205-209.

Ghassemi M R, Schmalholz S W and Ghassemi A R 2010 Kinematics of constant arc length folding for different fold shapes; J. Struct. Geol. 32 755-765.

Ghosh S K 1993 Structural Geology: Fundamentals and Modern Developments; Pergamon Press, Oxford, pp. 217 250.

Hudleston P L 1973 Fold morphology and some geometrical implications of theories of fold development; Tectonophys. $161-46$.

Hudleston P L and Lan L 1994 Rheological controls on the shapes of single-layer folds; J. Struct. Geol. $161007-$ 1021.

Hudleston P L and Treagus S 2010 Information from folds: A review; J. Struct. Geol. 32 2042-2071.

Johnson A M and Fletcher R C 1994 Folding of viscous layers: Mechanical analysis and interpretation of structures in deformed rock, Columbia University Press.

Lisle R J, Martínez J F, Bobillo-Ares N, Menéndez O, Aller J and Bastida F 2006 FOLD PROFILER: A MATLAB@based program for fold shape classification; Comput. Geosci. 32 102-108.

Liu C, Zhang Y and Wang Y 2009a Analysis of complete fold shape based on quadratic Bézier curves; J. Struct. Geol. 31 575-581.

Liu C, Zhang Y and Shi B 2009b Geometric and kinematic modeling of detachment folds with growth strata based on Bézier curves; J. Struct. Geol. 31 260-269.

Lorentz G G 1953 Bernstein polynomials; University of Toronto Press, 130p.

Marco A and Martínez J-J 2007 A fast and accurate algorithm for solving Bernstein-Vandermonde linear systems; Linear Algebra Appl. 422 616-628.

Misra A A and Mukherjee S 2017 Atlas of Structural Geological Interpretation from Seismic Images; Wiley Blackwell, ISBN: 978-1-119-15832-5.

Mukherjee S 2010a Structures in meso- and micro-scales in the Sutlej section of the Higher Himalayan Shear Zone, Indian Himalaya; e-Terra 7 1-27.

Mukherjee S 2010b Microstructures of the Zanskar Shear Zone; e-journal: Earth Sci. India 3 9-27. 
Mukherjee S 2011 Flanking Microstructures from the Zanskar Shear Zone NW, Indian Himalaya; YES Bull. 1 21-29.

Mukherjee S 2012 Simple shear is not so simple! Kinematics and shear senses in Newtonian viscous simple shear zones; Geol. Mag. 149 819-826.

Mukherjee S 2013 Higher Himalaya in the Bhagirathi section (NW Himalaya, India): its structures, backthrusts and extrusion mechanism by both channel flow and critical taper mechanisms; Int. J. Earth Sci. 102 1851-1870.

Mukherjee S 2014a Atlas of shear zone structures in mesoscale; Springer Geology. Cham., pp. 1-124.

Mukherjee S 2014b Review of flanking structures in mesoand micro-scales; Geol. Mag. 151 957-974.

Mukherjee S 2015 Atlas of Structural Geology; Elsevier, Amsterdam.

Mukherjee S and Koyi H A 2009 Flanking microstructures; Geol. Mag. 146 517-526.

Mukherjee S and Koyi H A 2010 Higher Himalayan Shear Zone, Sutlej section - structural geology and extrusion mechanism by various combinations of simple shear, pure shear and channel flow in shifting modes; Int. J. Earth Sci. 99 1267-1303.

Mukherjee S and Mulchrone K 2012 Estimating the viscosity of the Tso Morari Gneiss Dome, western Indian Himalaya; Int. J. Earth Sci. 101 1929-1947.

Mukherjee S, Talbot C J and Koyi H A 2010 Viscosity estimates of salt in the Hormuz and Namakdan salt diapirs, Persian Gulf; Geol. Mag. 147 497-507.

Mukherjee S, Punekar J, Mahadani T and Mukherjee R 2015 A review on intrafolial folds and their morphologies from the detachments of the western Indian Higher Himalaya; In: Ductile Shear Zones: From Micro- to Macro-scales (eds) Mukherjee S and Mulchrone K F, Wiley Blackwell, pp. 182-205.

Piegl L and Tiller W 1997a Symbolic operators for NURBS; Comp. Aided Design 29 361-368.

Piegl L and Tiller W 1997b NURB curves; Springer-Verlag, Berlin.

Salomon D 2007 Curves and Surfaces for Computer Graphics; Springer, 11p, ISBN 9780387284521.
Sederberg T W 2016 Computer Aided Geometric Design Course Notes; http://www.tsplines.com/educationportal. html.

Sederberg T W, Finnigan G T, Li X, Lin H and Ipson H 2008 Watertight trimmed NURBS; ACM Trans. Graphics 2779.

Sederberg T W, Zheng J, Bakenov A and Nasri A 2003 T-splines and T-NURCCs; ACM Trans. Graphics 22 477-484.

Sprague K B and de Kemp E A 2005 Interpretive tools for 3-D structural geological modelling part II: Surface design from sparse spatial data; Geoinformatica 9 5-32.

Srivastava D C and Lisle R J 2004 Rapid analysis of fold shape using Bézier curves; J. Struct. Geol. 26 1553-1559.

Srivastava D C, Rastogi V and Ghosh R 2010 A rapid Bézier curve method for shape analysis and point representation of asymmetric folds; J. Struct. Geol. 32 685-692.

Srivastava V and Gairola V K 1997 Classification of multilayered folds based on harmonic analysis: Example from central India; J. Struct. Geol. 19 107-112.

Stabler C L 1968 Simplified Fourier analysis of fold shapes; Tectonophys. 6 343-350.

Stowe C W 1988 Application of Fourier analysis for computer representation of fold profiles; Tectonophys. 156 303-311.

Tripathy A and Gairola V K 1999 Fold symmetry - a quantitative description; J. Struct. Geol. 21 719-727.

Turcotte D L and Schubert G 2002 Geodynamics; Cambridge University Press.

Twiss R J 1988 Description and classification of folds in single surfaces; J. Struct. Geol. 10 607-623.

Wills B and Willis R 1929 Geologic Structures; 2nd edn, McGraw-Hill Book Co., 518p.

Wojtal W 2001 Using Bezier curves to analyze the shapes of folded surfaces; Session No. 9, Structural Geology I: Faulting and Folding: Timing, Geometry, and Processes, GSA Annual Meeting, November 5-8, 2001.

Zhong D-H, Li M-C, Song L-G and Wang G 2006 Enhanced NURBS modeling and visualization for large 3D geoengineering applications: An example from the Jinping first-level hydropower engineering project, China; Comput. Geosci. 32 1270-1282. 